\title{
A COMPLEXIDADE DOS DESAFIOS DAS POLÍTICAS CURRICULARES EM EDUCAÇÃO DE JOVENS E ADULTOS NA ATUALIDADE
}

\section{LA COMPLEJIDAD DE LOS DESAFÍOS DE LAS POLÍTICAS CURRICULARES EN LA EDUCACIÓN DE JÓVENES Y ADULTOS EN LA ACTUALIDAD}

\author{
THE COMPLEXITY OF CURRENT CURRICULAR POLICY CHALLENGES IN \\ YOUTH AND ADULT EDUCATION
}

\author{
Raimundo Nonato Moura OLIVEIRA ${ }^{1}$ \\ Georgyanna Andrea Silva MORAIS ${ }^{2}$
}

RESUMO: O texto em tela desenvolve-se em torno do eixo discursivo denominado políticas curriculares em Educação de Jovens e Adultos (EJA), colocando em realce complexidade e desafios inerentes a essas políticas, mediante seu propósito de promoção de sua formação crítica conforme requerida na atualidade deste século XXI. Adota a análise histórico-dialética como referencial de pesquisa. Explica que toda proposta de formação na EJA, que visa superação de tensões, contradições e limites, implica compreendê-la dentro de sua perspectiva histórica, política, epistemológica e pedagógica, assim como das múltiplas práticas que a condicionam e de seus impactos na vida dos educandos que cursam essa modalidade de ensino, reconhecidos como personagens ativos de histórias de direitos negados.

PALAVRAS-CHAVE: Política curricular. Educação de jovens e adultos. Complexidade e desafios.

RESUMEN: El presente texto se desarrolla en torno al eje discursivo denominado politicas curriculares en Educación de Jóvenes y Adultos (EJA), destacando la complejidad y desafios inherentes a estas políticas, a través de su propósito de promover su formación crítica como se requiere en la actualidad de este siglo XXI. Adopta el análisis histórico-dialéctico como referencia de investigación. Explica que cualquier propuesta de formación en EJA, que pretenda superar tensiones, contradicciones y límites, implica comprenderla dentro de su perspectiva histórica, política, epistemológica y pedagógica, así como las múltiples prácticas que la condicionan y sus impactos en la vida de los ciudadanos. Alumnos que cursan esta modalidad de enseñanza, reconocidos como personajes activos en relatos de derechos negados.

PALABRAS CLAVE: Política curricular. Educación de jóvenes y adultos. Complejidad y desafios.

\footnotetext{
${ }^{1}$ Universidade Estadual do Maranhão (UEMA), Caxias - MA - Brasil. Professor Adjunto no Departamento de Educação. Doutorado em Educação (PUC/SP). ORCID: https://orcid.org/0000-0001-7038-8686. E-mail: kairosrn@hotmail.com

${ }^{2}$ Universidade Estadual do Maranhão (UEMA), Caxias - MA - Brasil. Professora Adjunta no Departamento de Educação. Doutora em Educação (UFC). ORCID: https://orcid.org/0000-0002-3609-7620 E-mail: georgyan_morais@yahoo.com.br
}

RPGE- Revista on line de Política e Gestão Educacional, Araraquara, v. 24, n. 3, p. 1350-1367, set./dez. 2020. e-ISSN:1519-9029 
ABSTRACT: The present text develops around the discursive axis called curricular policies in Youth and Adult Education (EJA, Portuguese initials), highlighting the complexity and challenges inherent to these policies, through its purpose of promoting their critical formation as required currently in this 21 st century. It adopts historical-dialectical analysis as a research reference. It explains that any proposal for training at EJA, which aims to overcome tensions, contradictions and limits, implies understanding it within its historical, political, epistemological and pedagogical perspective, as well as the multiple practices that condition it and its impacts on the lives of students taking this type of teaching, recognized as active characters in stories of denied rights.

KEYWORDS: Curricular Policy. Youth and adult education. Complexity and challenges.

\section{Introdução}

Atualmente, não faltam recomendações sobre a construção de políticas curriculares para a Educação de Jovens e Adultos, com vistas a garantir a estes sujeitos o direito à educação que, por circunstâncias, acertos e necessidades históricas, traduziu-se na condição de serem escolarizados, requerendo para isso, entre outras coisas, a melhoria do ensino, o acesso ao conhecimento e a formação de professores de modo qualitativo.

Porém, a concretização dessa realidade, se, por um lado, representa, do ponto de vista ético-político, uma obrigatoriedade, considerando os déficits históricos com essa população, da qual dependem as ações profissionais e coletivas da escola, por outro, as políticas curriculares continuam sendo uma realidade complexa enquanto não se compreende que essa modalidade de ensino tem especificidades próprias, cujo sentido da formação passa pela construção/desconstrução das experiências históricas, sociais e culturais dos educandos.

Várias pesquisas no Brasil acerca da Educação de Jovens e Adultos têm discutido a complexidade dos desafios que essa modalidade de ensino enfrenta historicamente para superar o processo de expulsão desses sujeitos pela escola (VÓVIO; MOURA; RIBEIRO, 2001; VÓVIO, 2009; SOARES, 2011; RÍVERO, 2009; DI PIERRO, 2005; DIAS et al., 2011). A leitura histórico-crítica desses desafios permite apontar a necessidade de que qualquer política de formação na EJA significativas de transformações implica compreendê-la dentro de uma perspectiva histórica, política, epistemológica e pedagógica, assim como das múltiplas práticas que a condicionam e dos seus impactos na vida dos educandos que vivem e cursam essa modalidade de ensino, reconhecidos como personagens ativos de histórias de direitos negados.

Nessa perspectiva, o que interessa neste texto sobre a questão da complexidade dos desafios das políticas curriculares na educação de jovens e adultos é a sua ampliação e compreensão como forma de conhecimento para refletir os processos de formação e promover 
mudanças nas práticas de ensinar e aprender dos educadores e educandos em sentido emancipatório.

\section{Aspectos históricos e a complexidade dos desafios curriculares na EJA}

A Educação de Jovens e Adultos (EJA), conforme estudos (BEISEIGEL 1974; 1997; 2000; 2003; FÁVERO, 2009) que embasam essa literatura aparece no contexto brasileiro como política educacional, a partir dos anos 40 do século XX, não obstante o entendimento de que a necessidade de oferecê-la se registra desde o período imperial, passando a ser historicizada somente no início do período republicano. Anteriormente a esse período, a Educação de Jovens e Adultos não constituía uma preocupação recorrente dos governos e aparecia nos textos normativos associada à educação de adultos e como educação geral, no sentido de direitos.

Carlos (2006) afirma que nas Constituições Federais (1891, 1934, 1937 e 1946) a educação de adultos apareceu tanto como precondição para o exercício político de votar, mediante a interdição do voto dos analfabetos no Brasil, quanto inserida no contexto do ensino primário, sob a responsabilidade dos estados e municípios pela sua criação e manutenção, cabendo à União apenas a tarefa de animá-la e promovê-la por meio de convênios com as unidades federativas.

Somente após 1940, a educação de adultos passa a ganhar referência na história da educação brasileira. Emerge como uma construção que nasce a partir do processo de industrialização, levando em conta fatores sociais, políticos, econômicos, culturais, permeada por um aspecto crítico e modernizante e por um tom participativo. Entretanto, sua intensificação ocorreu, a partir dos meados de 1980, quando problemas relativos aos jovens começam a ser estudados nas Ciências Sociais, dando realce à categoria juventude. É, assim, pois, que a designação Educação de Jovens e Adultos começa a ser utilizada na história (FÁVERO, 2009).

Portanto, o fenômeno educação de adultos, após a década de 40 do século XX, começa a ser percebido como um direito e passa a materializar-se em iniciativas concretas, como a criação do Fundo Nacional de Ensino Primário em 1942, do Serviço de Educação de Adultos e da Campanha de Educação de Adultos, ambos em 1947, da Campanha de Educação Rural iniciada em 1952 e da Campanha Nacional de Erradicação do Analfabetismo em 1958, tanto nos níveis estadual e local (FÁVERO, 2009). Todas visam oportunizar benefícios de escolarização a amplas camadas da população até então excluídas da escola, a partir de duas tendências orientadoras, a modernizante industrial e a crítico-emancipatória. 
Na perspectiva modernizante do capitalismo industrial, a escolarização é utilizada como mecanismo de conformação da classe trabalhadora ao paradigma societário, adequado aos interesses do processo de modernização do Estado-Nação e aos interesses do setor industrial de cada momento da história sociopolítica econômica e cultural do país. Quase todas as políticas públicas, voltadas para este campo de ensino, funcionaram como mecanismo de implantação de uma educação, que tem como eixo central a inserção do país numa economia que se globalizava (SHIROMA; MORAES; EVANGELISTA, 2004; FÁVERO, 2009).

Com as mudanças e a passagem do capitalismo industrial para o de mercado globalizado, o processo de escolarização continua a ser utilizado como mecanismo de conformação da classe trabalhadora, agora, dentro de um paradigma societário renovado pelo espírito neoliberal. Neste contexto predomina o discurso de implantação de uma "educação com qualidade" como condição tanto para a inserção do país numa economia globalizada, quanto para a promoção do desenvolvimento econômico com equidade social, conforme a declaração da Organização dos Estados Ibero-Americanos para a Educação, a Ciência e a Cultura (OEI, 1996).

Como se depreende, na perspectiva mercadológica, a inserção do país no contexto da reestruturação produtiva do capital depende de mão-de-obra com adequada formação para realizar um trabalho que atenda às especificidades do momento, portanto, torna-se necessário desenvolver a polivalência e a multifuncionalidade (PAIVA, 2009). A polivalência, entendida como capacidade do sujeito de exercer ou executar diferentes tarefas, isto é, ser versátil, desenvolvendo o seu potencial para exercer múltiplas funções, ou seja, ser multifuncional.

Nesse sentido, as políticas educacionais da atualidade direcionadas para a formação do público jovem e adulto têm como objetivo transformá-los em trabalhadores "competentes". Assim, a educação, adquirindo centralidade e associada a uma concepção produtivista, converge para a formação do jovem e adulto trabalhador pautada em competências sociais e cognitivas que lhes afeiçoam a perfis profissionais voltados para a nova configuração social (VIEIRA, 2000; VÓVIO; MOURA; RIBEIRO, 2001).

Na tendência crítico-emancipatória, ao contrário, o processo de escolarização é pensado e utilizado como mecanismo de conscientização e libertação das pessoas de suas condições sociais situadas e condicionadas. É uma escolarização pautada numa política educacional voltada à transformação social, assumindo uma posição contrária aos processos de educação na perspectiva de adaptação da população a processos de modernização conduzidos pelas forças políticas dominantes (BEISEIGEL, 1974; 2003). 
Essa tendência, em contraposição à efervescência política e cultural da tendência anterior nos seus diversos momentos históricos, construiu experiências no sentido de grupos populares articulados a sindicatos e a outros movimentos sociais, vinculados ao paradigma pedagógico gestado, no qual se defendia uma pedagogia dialógica como princípio educativo de libertação/emancipação dos educandos adultos e seu papel de sujeitos de aprendizagem, de produtores de cultura e de transformação do mundo (DI PIERRO; JOIA; RIBEIRO, 2001).

As atividades e iniciativas como o Movimento de Educação de Base (MEB) e o Movimento de Cultura Popular do Recife em 1961 dos Centros Populares de Cultura da União Nacional dos Estudantes, desenvolvidas sob a perspectiva emancipatória são variadas e, apesar das oposições e resistências das diferentes políticas historicamente dominantes, alcançaram experiências significativas de educação organizadas por diferentes atores e fundamentadas no paradigma da educação popular freireana.

A coexistência das duas tendências, a modernizante/mercadológica/produtivista e a crítico-emancipatória, como guia da Educação de Jovens e Adultos, tem feito com que, historicamente, esse campo de ensino venha se realizando com diferentes finalidades, vivenciando diversas concepções teóricas e práticas.

Ora, por um lado, servindo ao capital na perspectiva da formação de mão-de-obra qualificada para o trabalho, de acordo com as expectativas do mercado em cada momento da história. Nessa direção, as suas políticas públicas, a exemplo do MOBRAL em 1970, e sua legislação buscam atender aos interesses políticos e econômicos da classe dominante. Por outro, buscando a realização de uma educação que possa atender aos anseios de emancipação para a população brasileira, considerando-se que diferentes atividades como fóruns, conferências, seminários e encontros têm sido realizados a fim de construir propostas alternativas de ensino que superem os interesses do capital.

A crise com que se depara historicamente a Educação de Jovens e Adultos, não obstante investimentos recebidos, segundo Haddad (2009), Soares (2011), Arroyo (2005), Di Pierro (2005), revela que os impactos das políticas em torno desse campo de ensino, por motivos políticos, culturais, econômicos, sociais, dentre outros, não conseguiu efetivar sua trajetória de escolarização de forma democrática, atendendo à população no percurso que lhes é de seu direito. É uma modalidade de ensino que, segundo Arroyo (2005), apresenta-se como um campo aberto a todo cultivo de semeaduras nem sempre bem definido, ao longo de sua tensa história, portanto, indefinido e exposto a intervenções passageiras. Nesta acepção, tende a tornar-se um campo desprofissionalizado pela atuação de amadores, pela indefinição, pelo voluntarismo de 
campanhas emergenciais e de soluções conjunturais, aspectos que, no conjunto, caracterizam experiências negativas de sua história.

Estudos evidenciam que a inserção do Brasil no mundo globalizado e neoliberal trouxe mudanças significativas para o processo de escolarização da Educação de Jovens e Adultos (ARROYO, 2005; PAIVA, 2006; HADDAD, 2009; HADDAD; DI PIERRO, 2000). De um lado, porque o mercado demanda que a educação cumpra o seu papel de formação de mão-deobra competente para atuar nesse novo modelo econômico, caracterizado pelas novas formas de organização do trabalho. De outro lado, porque se exige a configuração de um campo específico de direitos e de responsabilidade pública do Estado capaz de responder a esse momento novo, bem como garantir os direitos específicos de tempos e percursos sociais, nos quais se revelam os limites e possibilidades de serem reconhecidos como sujeitos de direitos humanos.

Entretanto, mesmo com o discurso de uma educação de jovens e adultos voltada para atender às demandas do mercado e também garantir a efetivação de direitos sociais à educação, ao conhecimento, à cultura, à memória, à identidade, à formação e ao desenvolvimento pleno (Lei de Diretrizes e Bases da Educação Nacional, Lei no 9394/96, Art. $1^{\circ}$ e $2^{\circ}$ ), ainda persistem muitos desafios do ponto de vista do projeto cultural da escola pública. O currículo de formação para essa modalidade de ensino apresenta vários entraves, seja pelas dificuldades de se abrir para a multiplicidade de demandas que vêm da sociedade, seja pelas especificidades e necessidades dos próprios jovens e adultos.

Em que consiste a complexidade dos desafios para educação de Jovens e Adultos? Vários estudos acerca da Educação de Jovens e Adultos (EJA) têm revelado aspectos relevantes que caracterizam a complexidade da EJA, na perspectiva de uma formação significativa para esses sujeitos escolares, sobretudo, no sentido de superar o processo de abandono/expulsão escolar (HADDAD, 1992; 1997; 2009; OLIVEIRA, 1999). A discussão nesses estudos e pesquisas apontam explicações com ênfase em aspectos históricos, políticos, epistemológicos e pedagógicos, embora essas características, por vezes, se interpenetrem.

$\mathrm{O}$ aspecto histórico refere-se à ideia de saber historicamente quais tradições existem no campo que podem nos ajudar a responder às questões atuais de formação do público da EJA.

A esse respeito, Beiseigel (2003) aponta para a educação popular como uma rica fonte, dentre outras virtualidades, a ser examinada como alternativa para se pensar políticas de educação de jovens e adultos, analfabetos ou pouco escolarizados. Em sua opinião, as políticas de formação que parecem emergir dos projetos de educação popular praticados na atualidade, 
com poucas exceções, apontam para uma vida social marcada pelo respeito aos direitos da cidadania.

Di Pierro, Joia e Ribeiro (2001) ressaltam que, por impulsos diversos, a Educação de Jovens e Adultos (EJA) é convidada a reavaliar sua identidade e tradição. É instada a reelaborar seus objetivos e conteúdos de formação política para a cidadania democrática, a rever seus currículos inspirados no paradigma da educação popular, ao reconhecer o universo cultural dos educandos, e a questionar a valorização diferencial do conhecimento científico frente aos saberes construídos nas práticas de trabalho e na convivência no meio popular.

Esses autores defendem, nessa perspectiva, a importância histórica de incorporar ao currículo certos desafios éticos, políticos e práticos da vida social contemporânea, relacionados ao exercício da moderna cidadania. Colocam em realce a necessidade de qualificar os sujeitos por meio de ações culturais e políticas voltadas para o reconhecimento do valor da educação continuada e do ensino fundamental como estratégias de promoção de equidade educativa e social.

Diante dessas considerações, comporta evocar a observação de Paiva (2006, p. 13), ao asseverar que: "a educação como direito humano, continuadamente reafirmada, ganha força nas últimas décadas, mais no sentido das enunciações do que como o direito resguardado pelas políticas públicas, princípio indiscutível na EJA".

O fato que se impõe neste momento é que mesmo as pesquisas, contendo revelações sobre os avanços em relação à Educação de Jovens e Adultos (EJA), muito ainda há por se construir a fim de que a EJA se torne, concretamente, um direito básico para homens e mulheres, jovens e adultos, trabalhadores ou não. Por isso, é imperativo, diante destas considerações, inferir que a situação dessa modalidade de ensino, nas últimas décadas, se apresenta como uma questão de direito ainda não resolvido, apesar dos avanços obtidos.

Do ponto de vista político, os modos de pensar e agir, isto é, as opções que as instituições têm feito quanto ao controle, à seleção e à distribuição do conhecimento revelam-se como situações complexas e de grandes dificuldades, dadas as múltiplas e reais necessidades do público da EJA. Dentre as opções políticas que se revelam nesse campo de ensino, nessas últimas décadas, algumas refletem o desafio de reverter a enorme dívida social gerada por um modelo de desenvolvimento que não promove a justiça social.

Nessa direção, Di Pierro, Joia e Ribeiro (2001) ressaltam que o desenvolvimento de políticas de formação de pessoas jovens e adultos, consoante com o paradigma de educação continuada das agências formadoras, sobretudo, a escola, necessita, primeiro, reconhecer o direito dos indivíduos de traçarem, com autonomia, suas próprias biografias formativas. 
Segundo, modificar o estilo de planejamento, concebendo-o como oferta educativa, diante da diversidade de demandas concretas dos diferentes segmentos sociais. Terceiro, reconhecer que não apenas a escola, mas outras instituições e espaços sociais têm potencial formativo. Por isso, defendem a escolaridade mínima de responsabilidade do poder público, contando com a colaboração da sociedade civil organizada.

Além dessas demandas, esses autores referem-se ao estabelecimento de currículos mais flexíveis, capazes de integrar as dimensões de educação geral e profissional, de reconhecer processos de aprendizagem informais e formais e de combinar meios de ensino presencial e a distância de modo que os sujeitos possam adquirir novos aprendizados, bem como a certificação, conforme tenham se processado suas trajetórias formativas.

Ribeiro (1998) afirma que a demanda pela Educação de Jovens e Adultos (EJA) no nível de ensino fundamental é demasiadamente ampla e complexa, aspecto que comporta em seu interior uma gama diversificada de necessidades formativas. Em situações dessa natureza, geralmente, a opção é por políticas de formação aligeiradas. Nesse sentido, defende que, quando se pensa, por exemplo, em consolidar a alfabetização funcional, faz-se necessária uma escolaridade mais prolongada para formar usuários da linguagem escrita, capazes de fazerem dela múltiplos usos, com o objetivo de expressar a própria subjetividade, buscar informação, planejar e controlar processos e aprender novos conhecimentos.

Vários estudos, tendo como material de análise pesquisas sobre EJA, enfatizam que existe uma consensualidade entre os estudiosos acerca da necessidade de se apurar o olhar sobre questões próprias das etapas de vida de seus sujeitos, de suas relações com os processos de escolarização, de suas marcas de exclusão e de se ampliar suas especificidades para além da articulação com a categoria trabalho (DIAS et al., 2011).

A rigor, o que se constata dessa discussão é que os novos marcos dessa modalidade educativa, que se apresenta sob várias denominações -“educação alternativa”, “educação nãoformal", "educação para a vida e o trabalho", “educação contínua" -, revelam a ambiguidade e a inconsciência do campo educativo, assim como a imprecisão de enfoques que respondam especificamente à majoritária população juvenil nesse ensino, em seu projeto de formação (RIVERO, 2009). Na verdade, a compreensão é de que ainda predomina a visão compensatória, em que as formações são desenvolvidas na improvisação de espaços e com educadores, cuja visão de ensinar e aprender orienta-se por um modelo escolar pouco flexível e relevante. Ressalta, a propósito, que é precária a articulação do ensino básico de adultos com as políticas de renda mínima, assistência social, juventude, reforma agrária, meio ambiente, saúde, trabalho e não é levada em consideração a diversidade étnica e de gênero dos educandos. 
Predominam no cenário nacional políticas de formação, baseadas em programas e campanhas que, a exemplo do Programa Federal "Brasil Alfabetizado" em 2014, funcionou em bases tradicionais: organização em torno de um módulo de ensino-aprendizagem de curta duração, orientado estritamente à alfabetização; ausência de instrumentos de monitoração e avaliação de resultados; convocação de voluntários (sem nenhuma exigência de formação docente); não previsão de mecanismos que permitam a continuidade dos resultados em ciclos de educação básica, agregando-se a esses fatores pouca flexibilidade na organização de tempos e espaços, como a adequação dos módulos à realidade local (VÓVIO, 2006).

Considerando essa realidade, a compreensão é de que, nos dias atuais, do ponto de vista da política curricular de formação para a Educação de Jovens e Adultos, o grande desafio converge para o pensamento de que é necessário

[...] descentralizar o sistema de ensino e conceder autonomia aos centros educativos para que formulem projetos pedagógicos pertinentes às necessidades educativas das comunidades em que estão inseridos, convertendo-se estes no lócus privilegiado de desenvolvimento curricular (DI PERRO; JOIA; RIBEIRO, 2001, p. 71).

$\mathrm{Na}$ verdade, é importante destacar que as políticas de formação decididas em âmbitos institucionais externos à escola ou de iniciativas da própria escola, isto é, dos educadores e educandos, devem gestar uma formação que parta das necessidades dos sujeitos, sendo organizada e decidida no sentido de qualificação de sua atuação nas práticas sociais.

Comporta, pois, ratificar a recomendação internacional que enfatiza o processo de discussão da qualidade da educação a partir do reconhecimento de que a Educação de Jovens e Adultos (EJA) precisa ter uma definição clara de seus objetivos e estratégias político-didáticopedagógicas engendrados no reconhecimento da dinâmica da vida e da trajetória escolar dos educandos envolvidos (VI CONFINTEA, 2009).

A esse respeito, a consensualidade internacional acredita que é difícil a tarefa de mobilização de jovens e adultos para o retorno à escola e o desafio de fazê-los permanecer no sistema escolar. E há, ainda, um elemento fundamental que a Educação de Jovens e Adultos precisa considerar: fazer que os conhecimentos produzidos e difundidos nesse ensino sejam significativos, tenham qualidade e permitam aos educandos maior autonomia para se tornarem sujeitos da própria história (VI CONFINTEA, 2009).

Ao analisar, porém, vários aspectos inerentes a esse campo, aponta-se que fazer a articulação das ideias pessoais e biográficas com o conhecimento mais amplo torna-se, na atualidade, um ato desafiador do ponto de vista pedagógico. Esse desafio se deve ao fato de a 
formação ter se configurado como um valor em si mesma, razão pela qual os processos de formação apresentam múltiplas dimensões e intencionalidades, sobressaindo-se, contudo, a dimensão instrumental para o mercado de trabalho e emergindo como prerrogativa a incorporação no currículo do ensino fundamental de jovens e adultos a formação política para a cidadania moderna.

Quanto à dimensão epistemológica, definir o conhecimento que importa para ensinar e aprender nessa modalidade de ensino é uma questão que tem revelado dificuldades históricas, quando analisada do ponto de vista dos paradigmas existentes. A complexidade de orientações de paradigmas que envolvem esse campo de ensino faz com que este se configure como um território de práticas e reflexões que transcendem os limites da escolarização em sentido estrito. Isto vai engendrando processos formativos diversos, que oscilam, ora para iniciativas de desenvolvimento comunitário, ora para qualificação profissional, ora para a formação política e outras questões culturais, que em muitos casos deixam-no entrever como um campo indefinido. Além disso, contribui para que nem sempre os sujeitos da ação educativa sejam atendidos em suas necessidades formativas básicas de aprendizagem em meio aos seus contextos.

A literatura acerca desse âmbito de ensino aponta para a coexistência de alguns paradigmas deliberativos da ação curricular em EJA. O mais evidente, o paradigma tradicional, cânone da escola regular, com seus tempos e espaços, métodos, conteúdos e ritos rigidamente limitados, expressa um contínuo desconhecimento dos educandos como sujeitos que se engajam como atores sociais coletivos, de identidades, de projetos pessoais, por isso mesmo sujeitos de mudanças que fazem também os contextos mudarem (DIAS et al., 2011).

Esse paradigma com posturas homogeneizadoras reduz o educando à condição de aluno, visto na ótica da cognição (bom, esforçado, preguiçoso), ou na visão comportamental (disciplinado, rebelde), aspectos que impedem o conhecimento desses sujeitos como aprendizes em suas concretudes, forjados em contextos sociais, econômicos e culturais peculiares (DAYRELL, 1998), reduzindo-os continuamente à condição de crianças (OLIVEIRA, 1999).

Além disso, não são consideradas as diferentes trajetórias desses sujeitos: aqueles na condição de jovens ou adultos trabalhadores, adolescentes e jovens excluídos/expulsos do sistema regular ou que o abandonaram há algum tempo; aqueles que buscam a escola, motivados pelo ingresso no trabalho ou por ter cursado recentemente o ensino regular e acumularam defasagens entre idade e a série cursada (DI PIERRO; JOIA; RIBEIRO, 2001; OLIVEIRA, 1999). 
Outro paradigma presente no discurso curricular da educação de jovens e adultos é o modernizante, com o discurso de modernização da sociedade brasileira pelo processo de industrialização, de perspectiva produtivista e de matriz liberal, cuja concepção de educação, sobretudo, a escolar, consiste na preparação dos indivíduos para o ingresso, da melhor forma possível, na divisão social do trabalho, promovendo o aumento da produtividade, fator esse o mais importante para elevar o produto social e dessa maneira eliminar a pobreza na sociedade, e, consequentemente, a modernização da sociedade (SINGER, 1996; SHIROMA; MORAES; EVANGELISTA, 2004).

Sob a orientação desse paradigma, a compreensão é de que a EJA, do ponto de vista curricular, é considerada como um campo de segunda oportunidade para os sujeitos se redimirem e se ajustarem aos padrões modernos de desenvolvimento da sociedade. A esse propósito, o olhar para os sujeitos e sua formação orienta-se para a entrada no mercado de trabalho, o aumento das exigências de instrução e domínio de habilidades e competências. Além disso, visa atender às expectativas que os adultos e mais velhos têm de prolongar a escolaridade até o ensino médio para se inserir ou ganhar mobilidade no mercado de trabalho e nas práticas sociais, excluindo outras aprendizagens importantes (VÓVIO; MOURA; RIBEIRO, 2001).

No paradigma crítico-emancipatório, a abordagem do fenômeno educativo é ampla e sistêmica. Nesse sentido, a Educação de Jovens e Adultos é considerada como processo de fortalecimento da sociedade, da cidadania e um dos campos de ensino mais "[...] importantes aonde vêm se empreendendo esforços para a democratização do acesso ao conhecimento" (DI PIERRO; JOIA; RIBEIRO, 2001).

$\mathrm{O}$ que se depreende desse conjunto de orientações, que se fazem como guias deliberativos da ação curricular acerca do conhecimento na EJA, é que eles a colocam sob diferentes perspectivas, ora se realizando inspirada na educação popular (BEISEGEEL, 1974; 2000), ora como segunda oportunidade de caráter compensatório (DI PIERRO, 2005), e, atualmente, pensada como uma educação ao longo da vida (VI CONFITEA, 2009).

Constituída desse modo, a EJA, conforme revelam os estudos, apresenta-se como um campo fronteiriço (DI PIERRO; JOIA; RIBEIRO, 2001), indefinido, multifacetado, incerto, não consolidado nas áreas de pesquisa, de políticas públicas e de intervenções pedagógicas e aberto a todas as possibilidades (ARROYO, 2005). Estes aspectos têm dificultado para os agentes escolares, do ponto de vista epistemológico, o que considerar como conhecimento significativo a ser construído e como trabalhá-lo no processo de formação escolar. 
Na verdade, cada paradigma tem sua própria tradição na história da Educação de Jovens e Adultos e reflete um ponto de vista teórico-prático na organização escolar e no trabalho pedagógico.

O paradigma tradicional pensa a educação escolar baseada na tradição clássica de que a cultura "contém" certos conhecimentos e destrezas úteis que as escolas devem transmitir a fim de desenvolver os educandos para participarem da sociedade que os espera.

O paradigma modernista/produtivista de tendência mercadológica vê a escolarização como preparação para vida e para o trabalho, a partir de uma concepção de educando como pessoa em evolução. Também vê a sociedade aberta à reconstrução por meio dos cidadãos moralmente formados e capacitados para o trabalho, conforme seus princípios.

O paradigma crítico-emancipatório propõe que a Educação de Jovens e Adultos seja assumida como prática de liberdade e ofereça aos educandos formas de ação, de reflexão social e de políticas que apresentem modos de entendimentos e de luta para superar a estrutura social de injustiças, de irracionalidade e das privações de direitos sociais, políticos, econômicos.

Como se percebe, a mistura de tradições filosóficas na educação, ao entrecruzar o modo de pensar teórico-prático desse campo de ensino, torna problemático o processo de deliberação curricular quanto à tomada de posição acerca dos conhecimentos a serem considerados e trabalhados no processo de formação.

Di Pierro, Joia e Ribeiro (2001) afirmam que os requisitos formativos estão cada vez mais complexos para o exercício da cidadania plena, para as exigências crescentes por qualificações do mercado de trabalho excludente e seletivo e para as demandas culturais. Asseveram, ainda, que contemplar com equidade um direito básico da cidadania sob um parâmetro comum de qualidade de necessidades formativas diversas é um impasse e apontam como uma das saídas, com base na literatura nacional e internacional, superar a concepção de que a função prioritária ou exclusiva de EJA é a reposição de escolarização perdida na idade adequada.

Nesse sentido, esses autores defendem que os jovens e adultos sejam reconhecidos como sujeitos cognitivamente capazes de aprender ao longo de toda vida no âmbito das mudanças econômicas, tecnológicas e socioculturais em curso, exigindo a aquisição e atualização constante de conhecimentos em todas as idades. A formação deve ser caracterizada como processo que necessita ser abrangente, diversificado e flexível em face das necessidades múltiplas, diversas e cambiantes. 
A capacidade pedagógica de colocar o conhecimento curricular ao alcance dos educandos ainda permanece uma questão não resolvida. As pesquisas, ao tratar da formação escolar, revelam a Educação de Jovens e Adultos como campo de complexos desafios.

Dentre as várias questões decorrentes do aspecto da capacidade pedagógica, destaca-se a importância da flexibilização curricular que, segundo Di Pierro, Joia e Ribeiro (2001), precisa ser equivalente aos percursos formativos diversos e capaz de facultar aos educandos autodeterminarem suas biografias educativas, optando, inclusive, pela trajetória mais adequada às suas necessidades e características.

Nessa perspectiva, também a experiência internacional aponta para a flexibilização dos currículos e dos meios e formas de atendimento desses alunos, o reconhecimento de processos de aprendizagens formais e informais, a combinação de meios de ensino presenciais e a distância para que os indivíduos obtenham novas aprendizagens em suas diferentes trajetórias formativas (VI CONFINTEA, 2009).

Segundo Sérgio (2008), as dimensões tempo e espaço, como elementos da organização do currículo da formação na Educação de Jovens e Adultos (EJA), são bastante reduzidas concretamente. Estes fatos dificultam a escola desenvolver uma prática pedagógica em que os educandos possam depositar suas expectativas de aprendizagem, de ascensão social, de cidadania, de autoestima, de profissionalização e de superação do estigma de analfabetos. Isso resulta que o tempo como uma das variáveis mais importantes na prática pedagógica, proporcionando a organização e a materialização de um currículo, não tem contribuído para o empoderamento intelectual e social dos educandos de EJA. E, consequentemente, impossibilita uma apropriação de conhecimentos que os faça enfrentar e superar os desafios da sociedade e do contexto em que estão inseridos.

Di Pierro, Joia e Ribeiro (2001) acreditam que um dos elementos fundamentais para esse processo de colocar o conhecimento ao alcance dos educandos é aperfeiçoar os mecanismos de avaliação, facultando a crédito de aprendizagens os conhecimentos adquiridos na experiência pessoal e/ou profissional ou por meio de ensinos não-formais, diversificando e flexibilizando os meios de acesso a níveis de escolaridade mais elevados.

Desse modo, a articulação entre formação geral e profissional também tem se revelado como outro aspecto consensual entre as pesquisas e experiências nacionais e internacionais. Sabe-se que dentre as múltiplas motivações que jovens e adultos declaram ao participarem de programas formativos é a melhoria profissional e ocupacional que se destaca. E quando esse público é constituído por sujeitos que já atuam no mercado de trabalho essa articulação tornase mais difícil de ser sustentada (VI CONFINTEA, 2009). 
Nesse sentido, mesmo o trabalho perdendo a centralidade que teve no passado recente na construção das identidades dos sujeitos e grupos sociais, ele continua a ser fator importante nessa construção, haja vista apresentar-se como fonte exclusiva de prover a subsistência nas camadas populares empobrecidas.

\section{Considerações finais}

Após esta reflexão acerca da complexidade dos desafios das políticas curriculares para a EJA que resultam dos aspectos históricos, políticos, epistemológicos, pedagógicos e das múltiplas práticas que a condicionam e dos seus impactos na vida dos educandos, importa, num breve balaço, ressaltar algumas considerações que derivam dessa análise feita e que se trata de um conhecimento indispensável para ampliação e compreensão dos processos formativos como pontos de partida para outras reflexões que venham a ser feitas sobre as práticas de ensinar e aprender dos educadores e educandos, na atualidade deste século XXI.

Mesmo em se tratando de uma produção baseada em fundamentos teóricos e análise histórica, o conhecimento sobre o sentido das políticas curriculares, diante das constantes mudanças sociais, econômicas, tecnológicas, políticas e culturais, torna-se importante como orientador para pensar a formação escolar necessária aos tempos, espaços, relações e vivências aos quais estamos experimentando na sociedade contemporânea.

A relação do currículo com a prática social dos educandos remete-nos para o sentindo da construção curricular voltada para (re)localizar a vida social a uma realidade territorial de matriz comunitária, contrário ao movimento promovido pelo capitalismo industrial que busca constantemente, num espaço de conexões globais de homogeneização e fragmentação, proporcionar um processo de "desencaixe" das relações sociais dos contextos locais de interação, gerando uma crescente "desterritorialização" das nossas vidas (GIDDENS, 2011).

Nesse caso, trata-se de investir também em políticas curriculares que revalorizam o "local" como temática econômica, social e política, em um contexto dominado por conexões superficiais, por horizontes de curto prazo em uma racionalidade mercantil. É recriar reservas de confiança e de capital social, fundadas na convicção de que a cultura em perspectiva crítica conta como referência a uma necessária recontextualização da ação educativa escolar, marcando a importância das relações entre escola e o local (CANÁRIO, 2005).

Os complexos desafios curriculares discutidos, neste texto, revelam a importância da análise crítica que o contexto histórico e o contemporâneo têm nos processos de ensinar e aprender na escola para os que dela participam, a partir do contexto social local em dialogo com 
o global. Importa, assim, dizer que a escola necessita promover o debate profundo sobre a problemática da estrutura social e suas consequências para a vida das pessoas como ponto de partida de sua política curricular.

Considerando a intensidade das demandas e necessidades socioeconômicas que reclamam por políticas curriculares, torna-se necessário debruçar um olhar sobre temáticas que atendam a realidade atual e avaliar em que medida estas podem ser desenvolvidas sob processos críticos e contribuir para a construção dos estudos curriculares nessa modalidade de ensino, em vista do desenvolvimento dos educandos, a partir de uma nova relação com a sociedade.

$\mathrm{Na}$ verdade, trata-se da buscar, no âmbito da educação escolar de pessoas jovens e adultas, a criação de uma nova cultura curricular, na qual os educadores e educandos assumam também o papel de protagonistas ativos nas diversas fases que compõem o processo de formação: concepção, organização, acompanhamento e avaliação. É neste processo participativo e constante que, por mais complexa e difícil que seja a realidade, se geram as possibilidades de práticas curriculares transformadoras.

Desse modo, neste encerramento discursivo, dizemos que significa investir no desenvolvimento de uma política curricular capaz de promover uma formação de sujeitos com qualidades de compreensão crítica sobre a sociedade, de compromisso ético-político com proposição acerca de alternativas para melhorar e mudar o que não convém para a vida individual e coletiva. Além disso, de agir consciente e coletivamente, assumindo o seu lugar na história com predisposição para construir e renovar a cultura e o conhecimento diferente da hegemonia cultural elitista e excludente, sobretudo, com a autorreflexão sobre si em relação aos outros, alcançando consistência e coerência entre o que diz e faz no espaço escolar e na sociedade em que vivemos como pessoas, profissionais e cidadãos.

\section{REFERÊNCIAS}

ARROYO, M. G. Educação de Jovens e Adultos: um campo de direitos e de responsabilidade pública. In: SOARES, L. et al. (Org.). Diálogos na educação de jovens e adultos. Belo Horizonte: Autêntica, 2005. p. 19-50.

BEISEIGEL, C. R. Estado e educação popular: um estudo sobre a educação de adultos. São Paulo: Pioneira, 1974.

BEISEIGEL, C. R. Considerações sobre a política da união para a educação de jovens e adultos analfabetos. Revista Brasileira de Educação, São Paulo, n. 4, p. 26-34, jan./fev./mar./abr. 1997. 
BEISEIGEL, C. R. Questões de atualidade na educação popular: ensino fundamental de jovens e adultos analfabetos ou pouco escolarizados. Educação em Revista, Belo Horizonte, n. 31, p. 7-19, jun. 2000. Disponível em: http://educa.fcc.org.br/scielo. Acesso em: 3 dez. 2012.

BEISEIGEL, C. R. Alfabetização de jovens e adultos: desafios do século 21. Revista Brasileira de Estudos Pedagógicos, Brasília, v. 84, n. 206/207/208, p. 34-43, jan./dez. 2003. DOI: https://doi.org/10.24109/2176-6681.rbep.84i206-07-08.887

BRASIL. Lei n. 9.394, de 20 de dezembro de 1996. Estabelece as diretrizes e bases da educação nacional. Diário Oficial da união: Seção 1, Brasília, DF, p. 27833, 23 dez. 1996. PL 1258/1988

BRASIL. Ministério da Educação. Secretaria de Educação Continuada. Alfabetização e Diversidade. Documento Nacional Preparatório à VI Conferência Internacional de Educação de Adultos (VI CONFINTEA). Brasília: MEC; Goiânia: FUNAPE/UFG, 2009.

CANÁRIO, R. O que é a Escola? Um “olhar” sociológico. Portugal: Porto Editora, 2005.

CARLOS, E. J. O enunciado da educação de adultos no Brasil: da programação da República à década de 1940. In: REUNIÃO ANUAL DA ANPED, n. 29, 2006, Caxambu. Anais [...]. Caxambu, MG, 2006. 17 p. Disponível em:

http://www.anped.org.br/reunioes/29ra/trabalhos/trabalho/GT18-2344--Int.pdf. Acesso em: 12 set. 2012.

DAYREALL, J. T. Múltiplos olhares sobre a educação e cultura. Belo Horizonte: UFMG, 1998.

DI PIERRO; M. C. Notas sobre a redefinição da identidade e das políticas públicas de educação de jovens e adultos no Brasil. Educação e Sociedade, Campinas, v. 6, n. esp. 92, p. 1115-1139, out. 2005. DOI: https://doi.org/10.1590/S0101-73302005000300018

DI PIERRO; M. C.; JOIA, O.; RIBEIRO, V. M. Visões da educação de jovens e adultos no Brasil. Cadernos Cedes, Campinas, ano XXI, n. 55, p. 58-77, nov. 2001. DOI: https://doi.org/10.1590/S0101-32622001000300005

DIAS, F. et al. (Org.). Educação de jovens e adultos: o que revelam as pesquisas. Belo Horizonte: Autêntica Editora, 2011.

FÁVERO, O. Educação de jovens e adultos: passado de histórias; presente de promessas. In: RÍVERO; J.; FÀVERO, O. Educação de jovens e adultos na América Latina: direito e desafio de todos. São Paulo: UNESCO: Moderna, 2009.

GIDDENS, A. Mundo em descontrole: o que a globalização está fazendo de nós. Rio de Janeiro. Record, 2011.

HADDAD, S. Tendências atuais na educação de jovens e adultos. Em Aberto, Brasília, vol. 11, n. 4, p. 3-12, out./dez. 1992. 
HADDAD, S. A educação de pessoas jovens e adultas e a nova LDB. In: BRZEZINSKI, I. (Org.). LDB interpretada: distintos olhares se entrecruzam. São Paulo: Cortez, 1997.

HADDAD, S. A participação da sociedade civil brasileira na educação de jovens e adultos e na CONFINTEA VI. Revista Brasileira de Educação, Rio de Janeiro, v. 14, n. 41, p. 355369, maio/ago. 2009. Disponível em: http://www.scielo.br/pdf/rbedu/n14/n14a07.pdf. Acesso em: 2 jun. 2010.

HADDAD, S.; DI PIERRO, M. C. Escolarização de jovens e adultos. Revista Brasileira de Educação, Rio de Janeiro, n. 14, p. 108-130, maio/ago. 2000. Disponível em: http://www.scielo.br/pdf/rbedu/n14/n14a07.pdf. Acesso: em: 2 jun. 2011.

OEI. Organização dos Estados Iberoamericanos para a Educação, a Ciência e a Cultura. 1996. Disponível em: http: www.oei.es/educacion.php. Acesso em: 23 out. 2012.

OLIVEIRA, K. M. Jovens e adultos como sujeitos de conhecimento e aprendizagem. Revista Brasileira de Educação, São Paulo, v. 12, p. 59-73, 1999.

PAIVA, J. Direito à educação de jovens e adultos: concepções e sentidos. In: REUNIÃO ANUAL DA ANPED, n. 29, 2006, Caxambu. Anais [...]. Caxambu, MG, 2006. 17 p.

PAIVA, J. Os sentidos do direito à educação de jovens e adultos. Petrópolis, RJ: DP ET Alii/FAPERJ, 2009.

RIBEIRO, V. M. M. Alfabetismo e atitudes: pesquisa junto a jovens e adultos. Campinas, SP: Ação Educativa/Papirus, 1998.

RÍVERO, J. Alfabetização e Educação de Jovens e Adultos na América Latina, direito humano fundamental e fator social de equidade social. In: RÍVERO; J.; FÀVERO, O.

Educação de jovens e adultos na América Latina: direito e desafio de todos. São Paulo: UNESCO: Moderna, 2009.

SÉRGIO, M. C. A organização do tempo curricular na prática pedagógica da educação de jovens e adultos (EJA). Revista E-Curriculum, São Paulo, v. 3, n. 2, jun. 2008. Disponível em: http://www.pucsp.br/ecurriculum. Acesso em: 1 nov. 2012.

SHIROMA, E. O.; MORAES, M. C. M.; EVANGELISTA, O. Política educacional. Rio de Janeiro: DP\&A, 2004.

SINGER, P. Poder, política e educação. Revista Brasileira de Educação. Conferência de abertura da XVIII Reunião Anual da ANPEd, Caxambu, outubro de 1995, n. 1, p. 5-15, 1996.

SOARES, L. et al. (Org.). Diálogos na educação de jovens e adultos. Belo Horizonte: Autêntica, 2011.p. 7-17.

VIEIRA, M. C. Políticas de Educação de Jovens e Adultos no Brasil. Experiências e desafios no município de Uberlândia (anos 80 e 90). In: REUNIÃO ANUAL DA ANPED, n. 23, 2000, Caxambu. Anais [...]. Caxambu, MG, 2000. 24 p. 
VÓVIO, C. L. Alfabetização de pessoas jovens e adultas: outras miradas, novos focos de atenção. In: SAMPAIO, M. N.; ALMEIDA, R. S. (Org.). Práticas de educação de jovens e adultos: complexidade, desafios e propostas. Belo Horizonte: Autêntica, 2009. p. 296-324.

VÓVIO, C. L.; MOURA, M. P; RIBEIRO, V. M. Fundamentos da educação de jovens e adultos. Brasília: SESI, 2001.

\section{Como referenciar este artigo}

OLIVEIRA, R. N. M.; MARIAIS, G. A. S. A complexidade dos desafios das políticas curriculares em educação de jovens e adultos na atualidade. Revista on line de Política e Gestão Educacional, Araraquara, v. 24, n. 3, p. 1350-1367, set./dez. 2020. e-ISSN:1519-9029. DOI: https://doi.org/10.22633/rpge.v24i3.14167

Submetido em: 20/06/2020

Revisões requeridas: 28/07/2020

Aprovado em: 20/08/2020

Publicado em: 01/09/2020 